\title{
Article \\ Numerical Investigation of the Effects of the Beam Scanning Pattern and Overlap on the Temperature Distribution during the Laser Dopant Activation Anneal Process
}

\author{
Donghyeok Choi ${ }^{1}\left(\mathbb{D}\right.$ and Joonghan Shin ${ }^{1,2, *}$ (i) \\ 1 Department of Future Convergence Engineering, Kongju National University, 1223-24 Cheonandaero, \\ Seobuk-gu, Cheonan 31080, Korea; aaaengzz@daum.net \\ 2 Department of Mechanical and Automotive Engineering, Kongju National University, 1223-24 Cheonandaero, \\ Seobuk-gu, Cheonan 31080, Korea \\ * Correspondence: jhshin@kongju.ac.kr; Tel.: +82-41-521-9254; Fax: +82-41-555-9123
}

check for

updates

Citation: Choi, D.; Shin, J. Numerical Investigation of the Effects of the Beam Scanning Pattern and Overlap on the Temperature Distribution during the Laser Dopant Activation Anneal Process. Appl. Sci. 2021, 11, 10748. https://doi.org/10.3390/ app112210748

Academic Editors: Joohan Kim and Haewoon Choi

Received: 21 October 2021

Accepted: 10 November 2021

Published: 14 November 2021

Publisher's Note: MDPI stays neutral with regard to jurisdictional claims in published maps and institutional affiliations.

Copyright: (c) 2021 by the authors. Licensee MDPI, Basel, Switzerland. This article is an open access article distributed under the terms and conditions of the Creative Commons Attribution (CC BY) license (https:// creativecommons.org/licenses/by/ $4.0 /)$.

\begin{abstract}
Laser thermal annealing (LTA) has played an important role in the fabrication of scaled semiconductor devices by reducing the heat budget of the dopant activation process. During the laser annealing of entire wafer areas, the beam scanning pattern and overlap ratio have significant effects on uniform heating during the process. In this study, a numerical simulation of the LTA process was carried out using a three-dimensional transient heat transfer model. The temperature distribution produced by different laser scan paths and beam overlap ratios was analyzed. Additionally, the behavior of the dopant (phosphorus) diffusion induced under the multipath and beam overlapping conditions was numerically investigated. According to the simulation result, a zig-zag pattern generated hot spots around the corner areas of the beam path due to the greater heat accumulation per unit area; however, a bidirectional pattern induced cold spots due to the absence of laser heating around the corner areas. It was also found that the maximum temperature reachable in the beam overlapped region was much lower than that obtained along the beam scanning path, and the most uniform heating could be obtained when the zig-zag pattern and a $50 \%$ overlap ratio were used. According to the dopant diffusion and concentration distribution predicted for the case of the zig-zag pattern and 50\% overlap ratio, the difference in the dopant diffusion length was approximately thirty times within the scanned area.
\end{abstract}

Keywords: laser thermal annealing (LTA); numerical simulation; dopant activation; temperature distribution; multipath; beam overlap

\section{Introduction}

As the size of complementary metal oxide semiconductor (CMOS) devices is continuously scaled down, the junction depths of these devices become shallower. In a shallow junction, an abrupt doping profile which can provide low resistance is crucial to improve the electrical performance of the device [1-3]. In general, activation of the dopant increases with the temperature and time of the activation anneal process. On the other hand, this enhances the diffusion of the dopant, which in turn can restrict the formation of the abrupt doping profile and induce a detrimental short-channel effect in the device. Therefore, a relevant annealing technique for dopant activation is essential for the fabrication of scaled devices $[4,5]$.

Conventionally, a rapid thermal process (RTP) [6,7] using halogen lamps for heating has been widely applied for dopant activation annealing of the junction area; however, the annealing time for RTP is generally tens of seconds, representing a large heat budget for scaled devices requiring the formation of a shallow junction. In order to reduce the thermal budget and minimize undesired dopant diffusion, millisecond annealing (MSA) technologies such as flash lamp annealing (FLA) and laser thermal annealing (LTA) have 
been developed. An advantageous feature of MSA is that only the surface region of the wafer is heated to a high temperature while the temperature of the remaining bulk area of the wafer remains significantly lower, acting as a heat sink for thermal energy [8-10]. This mechanism rapidly dissipates the heat of the annealed region through conduction heat transfer, thus limiting dopant diffusion. Lanzerath et al. [11] reported experimental results of dopant activation and diffusion behavior for both standard RTP and FLA. It was found that the FLA method formed an ultra-shallow junction (USJ) without significant dopant diffusion.

However, for FLA, radiation heat from the lamp is transferred throughout the wafer. If there is a very large temperature (usually hundreds of degrees) difference between the front and back surface of the wafer, severe wafer warpage resulting in breakage of the wafer can arise [12]. On the other hand, the heat in LTA is only confined to local and shallow surface regions of the wafer; hence, there is no warpage of the wafer when using this process. This characteristics of the laser radiation also allow reducing thermal effects in other laser-based processes [13,14].

To date, various studies of dopant activation by LTA have been conducted. Luong et al. [15] studied the activation and diffusion of As in SiGe/Si heterostructure layers during an excimer laser annealing process. It was found that SiGe layer melting was necessary to achieve low sheet resistance and high dopant activation. However, the melting induced more dopant diffusion into the bulk region. Sharyesteh et al. [16] compared the effects of LTA and RTP on the dopant activation outcome in phosphorus-doped Ge. It was found that the activated carrier concentration increased by approximately $270 \%$ when LTA was used. Shima et al. [17] reported laser spike annealing (LSA) using a $\mathrm{CO}_{2}$ laser as a light source. According to their study, the LSA process produced better electrical performance (i.e., a larger drain current and lower sheet resistance) of a CMOS device compared to RTP owing to the higher heating temperature and shorter annealing time. It was also found that the LSA could achieve good heating uniformity without the need for additional layers. The dual-beam laser spike annealing (DB-LSA) technique was introduced to expand the application space of LSA [18]. In DB-LSA, a second beam is used to preheat the wafer. Based on a series of tests, it was found that the DB-LSA process produces lower thermal stress and has greater defect curing capabilities compared to conventional LSA.

The temporal and spatial profiles of the temperature at the annealed area during the LTA process are the key factors determining the degrees of dopant activation and diffusion. In addition, information about the temperature is essential for a proper understanding of the fundamental physical phenomena relating to the process. However, precise measurements of the temperature history in the LTA process are usually very difficult due to the short anneal time and small laser spot. Therefore, a numerical simulation for predicting the temperature distribution reasonably during LTA is necessary.

Jung et al. [19] performed numerical simulation of the pulsed laser annealing process to investigate the number of pulses required to form an optimal ultra-shallow junction (USJ). It was found that the optimal USJ was obtained when eight laser pulses were irradiated at an energy density level of $130 \mathrm{~mJ} / \mathrm{cm}^{2}$. Florakis et al. [20] carried out experimental and numerical studies of non-melt excimer laser annealing to form the USJ in boron-implanted silicon. The evolution of the temperature distribution along the surface and volume of the material were calculated to analyze the boron kinetics and activation.

Shin et al. [21] conducted numerical simulations to predict the melting depth of phosphorus-doped silicon at different laser energy densities. It was found that the total melting (65 nm melt depth) of the phosphorus-doped silicon occurred when the laser energy density was between 620 and $640 \mathrm{~mJ} / \mathrm{cm}^{2}$. Colin et al. [22] undertook a simulation to evaluate thermal pattern effects for various stacks and structures. According to their simulation results, a shallow trench insolation (STI) oxide layer was critical for inducing a large temperature variation. It was also found that the temperature was highly dependent on the STI density and length. 
As described above, various numerical studies of LTA have been conducted with different purposes. However, in most studies, simulations of the LTA process were carried out under very limited conditions (a fixed beam position or a single pulse), with the results not providing enough information about the phenomena occurring during the actual annealing process. In actual applications of the LTA process, the scanning pattern of the laser beam and the related beam overlap are very important for achieving a uniform temperature and proper dopant activation throughout the wafer area. The purpose of this study is to investigate the temperature distributions created by different laser scan paths and beam overlaps. For a thermal analysis of the LTA process, a numerical simulation of the LTA process was conducted with the time-dependent heat transfer module of COMSOL Multiphysics (commercial software). The spatial and temporal temperature distributions during multi-pass laser annealing were determined through a numerical simulation. Based on the calculated temperature information, the dopant diffusion and concentration in silicon were also predicted.

\section{Development of a Numerical Model}

\subsection{Computational Domain and Scanning Pattern}

In this study, a numerical simulation using the time-dependent heat transfer module of COMSOL Multiphysics (version 5.5) was conducted to analyze the temperature distribution during laser dopant activation annealing. The computational domain used in the simulation is presented in Figure 1. The size of the computational domain is $7.5 \mathrm{~mm} \times 2.7 \mathrm{~mm} \times 0.75 \mathrm{~mm}$ (length $\times$ width $\times$ height). Through preliminary numerical tests, it was found that the temperature change at the boundary of $x$ and $y$ direction computational domain $(7.5 \mathrm{~mm} \times 2.7 \mathrm{~mm})$ was negligible. The real thickness of a commercial wafer was adopted for the height of the computational domain. In order to increase the accuracy of the calculation, the area irradiated by the laser beam was finely meshed to a size of $40 \mu \mathrm{m}$. For the surrounding area, a growth-distributed mesh capable of increasing the mesh size was adopted to reduce the computation time. In this simulation, two scanning patterns (zig-zag and bidirectional pattern) were tested, as shown in Figure 2. The dashed line with the arrows indicates the scanning path of the laser beam. $\Delta x(4 \mathrm{~mm})$ represents the distance at which the laser beam scans along the $x$-axis direction. $\Delta y$ is the distance between two adjacent scan tracks, and it varies from $200 \mu \mathrm{m}$ to $400 \mu \mathrm{m}$ according to the beam overlap ratio $(0-50 \%)$. For the zig-zag pattern, the laser beam continuously irradiates the surface along the scan paths. On the other hand, for the bidirectional pattern, the laser beam is switched off when it moves in the $y$-axis direction. The laser beam is again switched back on as it proceeds to the next track.

\subsection{Governing Equation}

The governing equation of the transient heat conduction model for the LTA process is expressed as:

$$
\rho C_{p} \frac{\partial T}{\partial t}=\frac{\partial}{\partial x}\left(k \frac{\partial T}{\partial x}\right)+\frac{\partial}{\partial y}\left(k \frac{\partial T}{\partial y}\right)+\frac{\partial}{\partial z}\left(k \frac{\partial T}{\partial z}\right)+Q
$$

where $\rho$ is the density $\left(\mathrm{kg} / \mathrm{cm}^{2}\right), C_{p}$ is the specific heat capacity $(\mathrm{J} / \mathrm{kg} \cdot \mathrm{K}), T$ is the temperature $(\mathrm{K}), k$ is the thermal conductivity $(\mathrm{W} / \mathrm{m} \cdot \mathrm{K})$, and $Q$ is the heat source per unit volume $\left(\mathrm{W} / \mathrm{m}^{3}\right)$, which corresponds to the laser energy absorbed by the sample. 


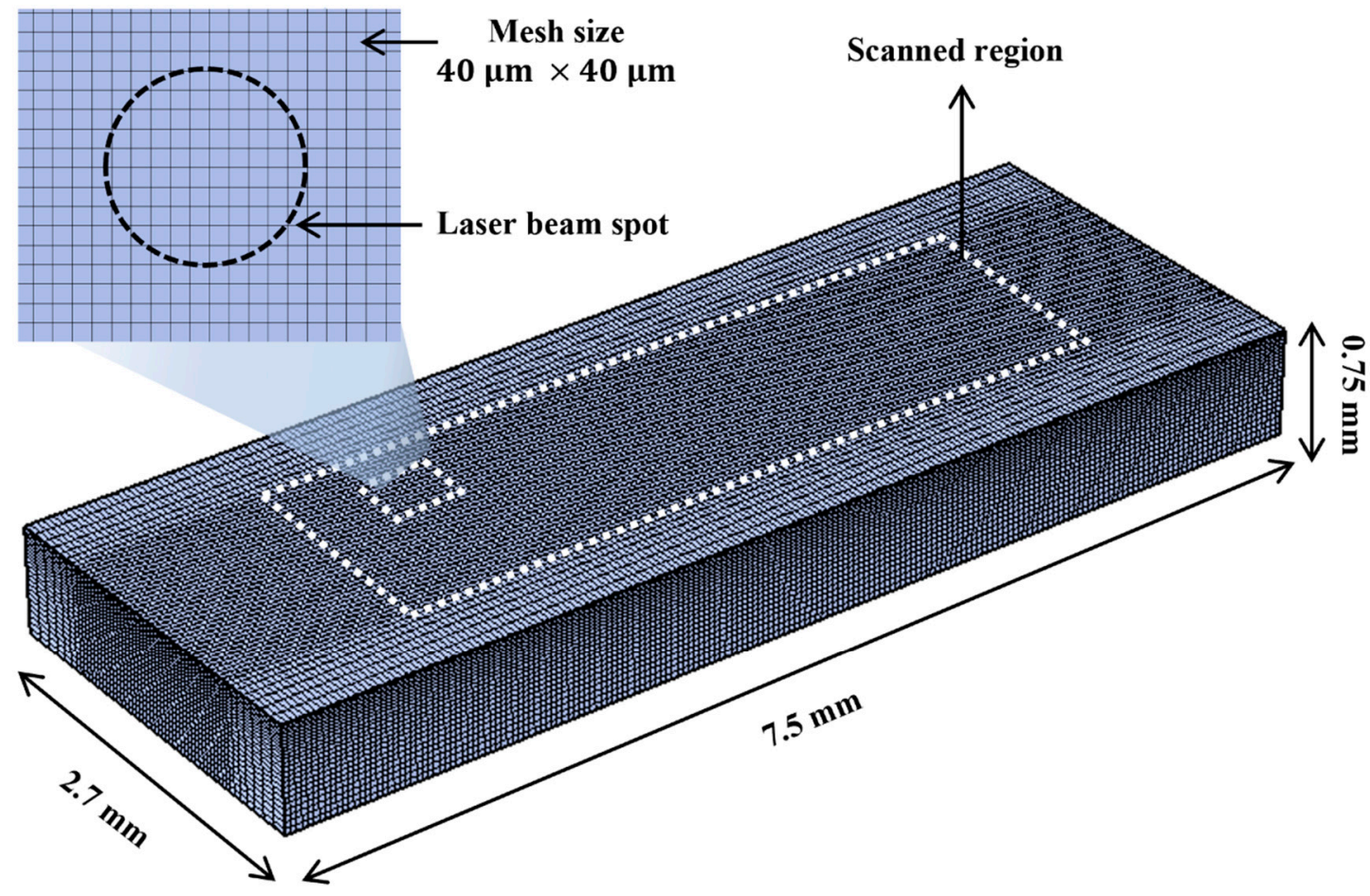

$y+x$

Figure 1. 3D finite element model used in this study.

(a)

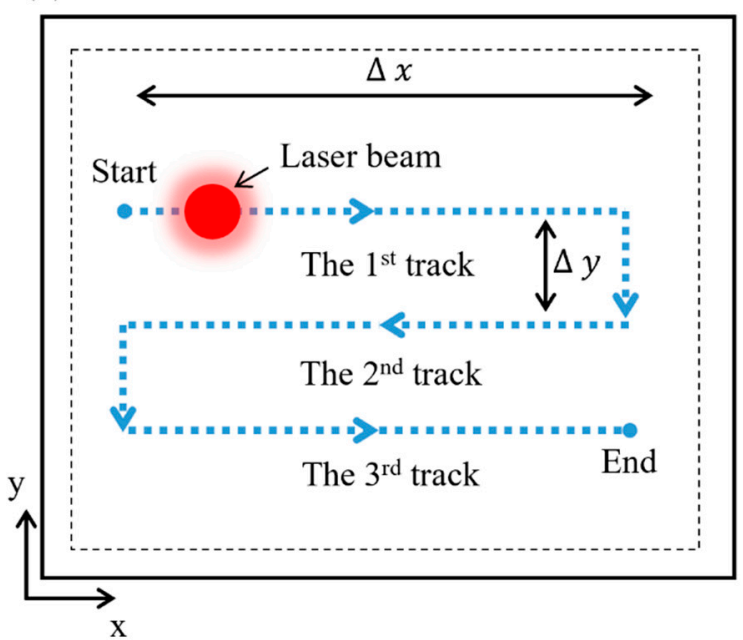

(b)

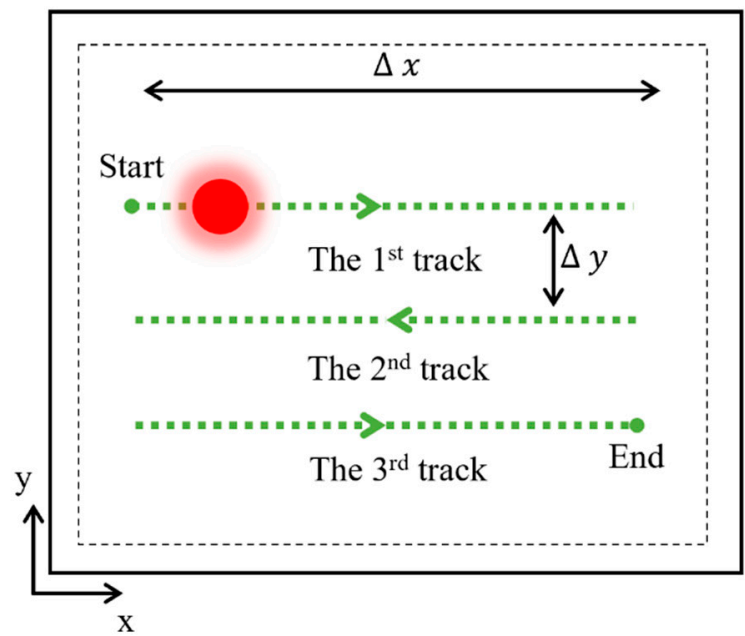

Figure 2. Scanning patterns used in simulation: (a) zig-zag pattern and (b) bidirectional pattern.

\subsection{Boundary and Initial Condition}

In order to solve Equation (1), reasonable boundary conditions should be defined. The energy losses due to convective and radiation heat transfer were considered at the top surface of the computational domain. The boundary condition of the top surface is as follows:

$$
-k \frac{\partial T}{\partial \vec{n}}=h\left(T-T_{a m b}\right)+\varepsilon \sigma\left(T^{4}-T_{a m b}^{4}\right)
$$

where $\vec{n}$ is the surface normal vector, $h$ is the convective heat transfer coefficient $\left(10 \mathrm{~W} / \mathrm{m}^{2} \cdot \mathrm{K}\right), T_{a m b}$ is the ambient temperature $(303.15 \mathrm{~K}), \sigma$ is the Stefan-Boltzmann 
constant $\left(5.67 \times 10^{-8} \mathrm{~W} / \mathrm{m}^{2} \cdot \mathrm{K}^{4}\right)$, and $\varepsilon$ is the surface emissivity $(0.7)$, respectively. In this study, it was assumed that no heat transfer occurred through any of the side walls of the computational domain. Therefore, an adiabatic condition was applied to all side walls of the computational domain, as follows:

$$
-k \frac{\partial T}{\partial \vec{n}}=0
$$

In the simulation, it was also assumed that wafer was uniformly preheated. In general, wafer preheating is used to enhance the absorption rate of the laser beam in wafer (see Section 2.5. to check the effect of preheating in detail). A preheat temperature of $400{ }^{\circ} \mathrm{C}$ was applied in the model. Thus, the initial condition of the simulation is expressed as follows:

$$
\left.T\right|_{t=0}=T_{0}=400^{\circ} \mathrm{C}
$$

where $T_{0}$ is the initial temperature of the wafer.

\subsection{Heat Source}

The heat source $Q$ can be expressed as Equation (5) using the Beer-Lambert law [23]:

$$
Q(x, y, z)=\alpha I_{0}(1-R) \exp (-\alpha|z|)
$$

In this equation, $R$ is the reflectance of the material surface, $\alpha$ is the absorption coefficient $\left(\mathrm{cm}^{-1}\right)$ and $I_{0}$ is the incident laser intensity $\left(\mathrm{W} / \mathrm{m}^{2}\right)$. The intensity of the incident laser beam was assumed to have a Gaussian distribution, as follows:

$$
I_{0}=\left(\frac{2 P_{0}}{\pi r_{b}^{2}}\right) \exp \left[-2\left(\frac{\left(x-x_{0}\right)^{2}}{r_{b}^{2}}+\frac{\left(y-y_{0}\right)^{2}}{r_{b}^{2}}\right)\right]
$$

where $P_{0}$ is the laser power, $r_{b}$ is the effective laser beam radius, and $x_{0}$ and $y_{0}$ are the center coordinates of beam spot.

\subsection{Material Properties and Process Conditions}

It has been reported that a $\mathrm{CO}_{2}$ laser with a long wavelength $(\lambda=10.6 \mu \mathrm{m})$ can reduce the pattern effect and produce a relatively uniform temperature distribution within a chip owing to its low photon energy and resultant absorption mechanism [24]. Due to this advantage of the $\mathrm{CO}_{2}$ laser, it is considered as an ideal light source for the annealing of semiconductor devices [25-27]. In this study, it was assumed that the laser beam for dopant activation annealing has a wavelength of $10.6 \mu \mathrm{m}$.

In the far-infrared (FIR) light source considered in this study, the absorption mechanism in silicon undergoes a type of intra-band excitation known as free carrier absorption [28]. In this absorption mechanism, the absorption rate increases with an increase in the population of the free carriers in the material. Therefore, increasing the population of free carriers is vital for the efficient use of the laser energy during the LTA process. The population of free carriers can be increased through doping [29] and preheating [30] of the wafer (i.e., by increasing the dopant concentration and temperature of the wafer). According to Blomberg et al. [31], the absorption coefficient can be expressed as a function of the dopant concentration and temperature, as follows:

$$
\alpha(N, T)=1.9 \times 10^{-20}(T)^{3 / 2} \times\left[N+n_{i}(T)\right]+2
$$

where $N$ is the dopant concentration $\left(\mathrm{cm}^{-3}\right), T$ is the temperature $(\mathrm{K})$, and $n_{i}(T)$ is the temperature-dependent intrinsic carrier concentration $\left(\mathrm{cm}^{-3}\right)$, which is given by:

$$
n_{i}(T)=3.87 \times 10^{16}\left(\frac{T}{300}\right)^{3 / 2} \exp \frac{-7020}{T}
$$


In this simulation, the dopant concentration was assumed to be $4.5 \times 10^{19} \mathrm{~cm}^{-3}$.

The thermo-physical and optical properties used in the simulation are summarized in Table 1. Temperature-dependent values were adopted for the main thermo-physical properties, in the case the thermal conductivity and specific heat. The spot size of the beam was $400 \mu \mathrm{m}$, and a fixed laser power $(105 \mathrm{~W})$ and scanning speed $(400 \mathrm{~mm} / \mathrm{s})$ were used in the simulation. Several numerical tests were performed according to the process conditions. Details of each test condition are given in Table 2.

Table 1. Optical and thermo-physical properties of silicon.

\begin{tabular}{ccc}
\hline Parameters & Value & Reference \\
\hline & $4.19 \times 364\left(T^{-1.226}\right)$ for $T<1200 \mathrm{~K}$ & \\
$k(\mathrm{~W} / \mathrm{cm} \cdot \mathrm{K})$ & $9 \times T^{-0.502}$ for $1200 \mathrm{~K}<T<1600 \mathrm{~K}$ & \\
& 0.221 for $1600 \mathrm{~K}<\mathrm{T}$ & [32] \\
$C_{p}(\mathrm{~J} / \mathrm{g} \cdot \mathrm{K})$ & $0.695 \times \exp \left(2.375 \times 10^{-4} T\right)$ & \\
$\rho\left(\mathrm{g} / \mathrm{cm}^{2}\right)$ & 2.3 & [33] \\
$R$ & 0.3 for $\lambda=10.6 \mu \mathrm{m}$ & \\
\hline
\end{tabular}

Table 2. Process conditions used in the simulation.

\begin{tabular}{ccccc}
\hline Test No. & Scan Pattern & Overlap Ratio (\%) & Laser Power (W) & Scan Speed (mm/s) \\
\hline 1 & Zig-zag & 0 & & \\
2 & & 50 & 105 & 400 \\
3 & Bidirectional & 0 & & \\
4 & & 50 & & \\
\hline
\end{tabular}

\subsection{Equation for Dopant Concentration Distribution}

During laser annealing, the implanted dopants are activated, and simultaneously diffuse in silicon. Severe diffusion in the junction area can induce the detrimental short channel effect, which significantly increases the leakage current in the junction area.

In this study, an investigation of the dopant concentration distribution is also conducted to understand the aspect of dopant diffusion during laser annealing based on the temperature determined by a simulation. For this analysis, it is assumed that the dopant implanted into the silicon wafer is phosphorus and that it is implanted at $30 \mathrm{keV}$ with a dose of $1 \times 10^{15} \mathrm{~cm}^{-2}$.

According to earlier work [34], the dopant concentration distribution can be expressed as:

$$
N(x, t)=\frac{Q}{\sqrt{2 \pi\left(\sigma^{2}+2 D t\right)}} \exp \left(-\frac{\left(x-R_{P}\right)^{2}}{2\left(\sigma^{2}+2 D t\right)}\right)
$$

where $N(x, t)$ is the dopant concentration at a depth of $x(\mathrm{~nm})$ and annealing time $t$ (msec), and $Q$ is the dose $\left(\mathrm{cm}^{-2}\right) . R_{P}$ is the projected range of the implanted dopant $(\AA), \sigma$ is the standard deviation in the projected range $(\AA)$, and $D$ is the diffusivity of the dopant $\left(\mathrm{cm}^{2} / \mathrm{s}\right)$.

In this study, the annealing time, defined as the beam spot size divided by the scan speed, was $1 \mathrm{msec}$, and the values of $R_{P}$ and $\sigma$ were adopted from work by Gibbons et al. [35] for the case of the phosphorus and $30 \mathrm{keV}$ of energy. The adopted values for $R_{P}$ and $\sigma$ were $37.2 \mathrm{~nm}$ and $12.6 \mathrm{~nm}$, respectively.

In Equation (9), the diffusivity, D, can be expressed as follows [36]:

$$
D=D_{0} \exp \left(\frac{-E_{a}}{k_{B} T}\right)
$$

where $D_{0}$ is the pre-exponential factor $\left(1.44 \mathrm{~cm}^{2} / \mathrm{s}\right), E_{a}$ is the activation energy $(2.69 \mathrm{eV})$ and $k_{B}$ is the Boltzmann constant $\left(8.617 \times 10^{-5} \mathrm{eV} / \mathrm{K}\right)$. $T$ is the temperature taken from the simulation results of this study. Based on Equation (9) and the temperature data taken 
from the simulation results, dopant concentration distribution during the laser annealing process is estimated.

\section{Results and Discussion}

\subsection{Analysis of the Surface Temperature Distribution}

The temporal profiles of the maximum surface temperature (the temperature at beam spot center) under different simulation conditions are shown in Figure 3. Early in the annealing process, the temperature increases significantly. However, the temperature becomes quickly stabilizes in a few milliseconds, and it mostly does not change until the first scanning track of the laser beam ends. When the laser beam moves along the $y$ direction, the temperature increases dramatically (for zig-zag pattern) or decreases (for bidirectional pattern) depending on the scanning pattern. At the corner region of the scanning track, the zig-zag pattern produces a hot spot due to the greater heat accumulation per unit area. For the overlap ratio of $50 \%$, the maximum temperature at near the starting point of the second track increases by approximately $22^{\circ} \mathrm{C}$ more compared to that at an overlap ratio of $0 \%$ because the preheating effect at the end of the first track is substantial. A temperature fluctuation is observed between the end of the first track and the start of the second track when the overlap ratio is $0 \%$. A decrease in the temperature in this region occurs as the beam spot leaves the area preheated by the first track. Unlike the zig-zag pattern, the bidirectional pattern generates a cold spot because the laser beam is switched off between the first and second scanning tracks. The temperature reduction is more significant (decreases approximately $129^{\circ} \mathrm{C}$ more) when beam overlapping is not used, as shown in Figure $3 c$,d. It was also found that at an overlap ratio of $0 \%$, more time is required for the temperature to recover to the previous level. Table 3 shows the temperature change induced by the corner zone of the beam path. As shown in the Table 3, the bidirectional scanning pattern at an overlap ratio of $0 \%$ causes the largest temperature difference, which in turn worsens the temperature uniformity.

The beam overlap effect in sequentially scanned lines was also investigated. Figure 4 shows the temperature with time at the midpoints (points 1 and 2 in Figure 4) between two adjacent scanned lines. At the beginning of the annealing process, the temperatures at the designated points are nearly constant given that these points are far from the start pointing of the annealing. However, as the laser beam approaches points 1 and 2, the temperature at point 1 rises rapidly, as shown in the figure. The temperature of point 2 also increases with a slight time lag, although the degree of the temperature increase is relatively small. This indicates that annealing of the first track could preheat the second and third tracks. As shown in Figure 4, the maximum temperature of the peaks (the three high peaks shown in graphs) tends to increase slightly owing to the effect of the preheating induced by the scanning of the former track. When the laser beam scans the second track, points 1 and 2 undergo rapid increases and decreases of the temperature, with the temperature variations at the two points being identical regardless of the simulation condition, as shown in the figure. During the scanning of the third track, the temperature of point 2 increases greatly again as the laser beam approaches point 2, with the temperature at point 1 also increasing slightly with a time lag, as shown in the figure. The temperature profiles do not change much according to the difference in the scanning pattern. However, the temperature difference caused by the degree of beam overlapping is considerable. At an overlap ratio of $50 \%$, the temperature of the peaks increases by approximately $54 \%$ compared to that at an overlap ratio of $0 \%$. It was also found that the $50 \%$ overlap ratio condition generates higher heating and cooling rates than the $0 \%$ overlap ratio condition. The differences between the heating and cooling rates in the $0 \%$ and $50 \%$ overlap conditions are $130 \%$ and $150 \%$, respectively (see Table 4). From the results shown in Figures 3 and 4, it can be concluded that the difference in the maximum temperature reachable at all locations throughout the computational domain is smallest when the zig-zag pattern and 50\% overlap ratio are used. This indicates that the most uniform heating outcome can be realized when these conditions are used. 
(a)

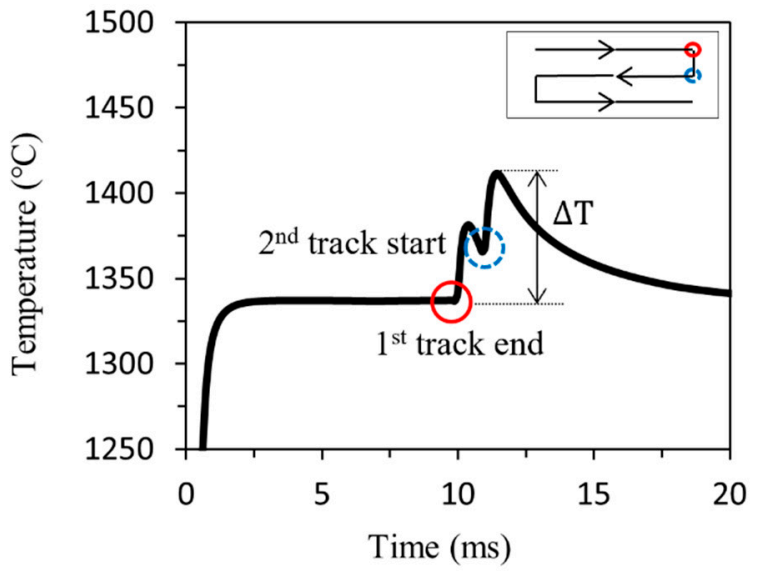

(c)

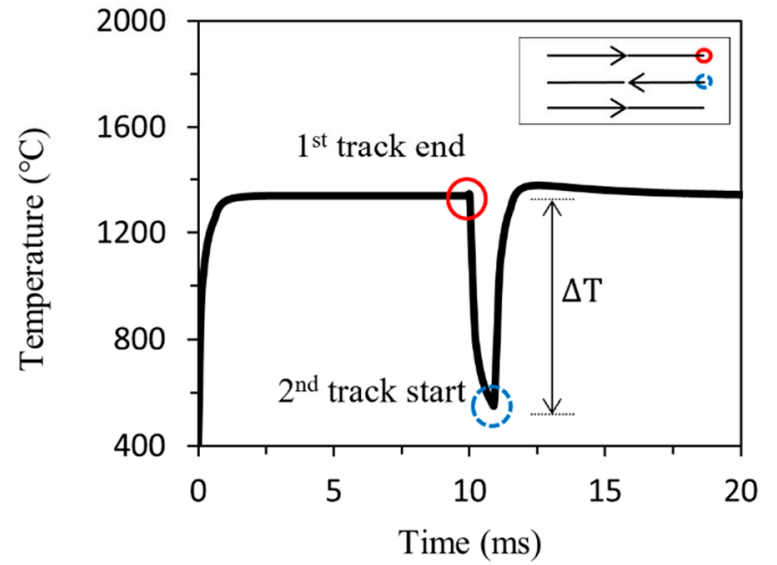

(b)

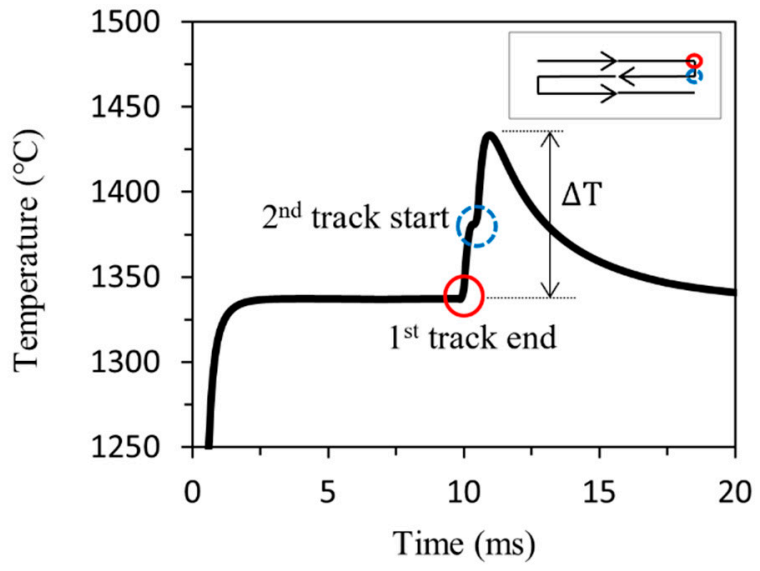

(d)

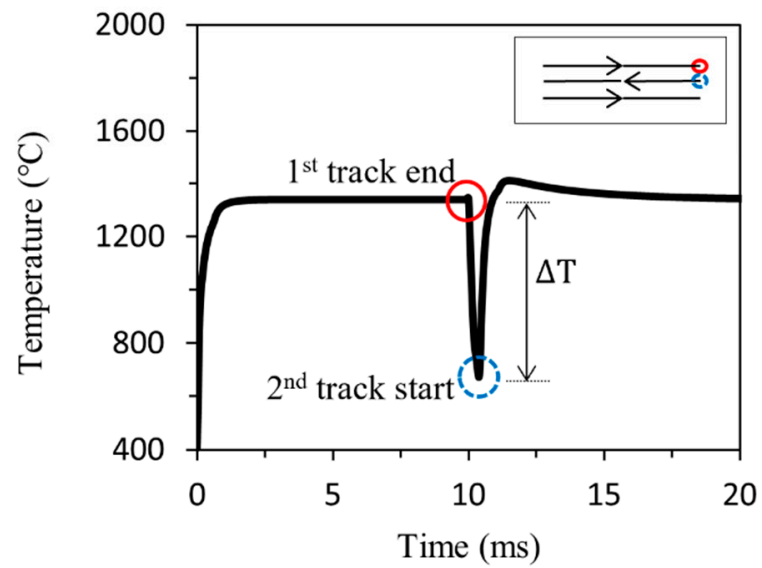

Figure 3. Temperature at the center of the beam spot as a function of time: (a) test 1, (b) test 2, (c) test 3 and (d) test 4 (red and blue circle in the figure indicate the end of the 1st track and the start of the 2nd track, respectively).

Table 3. Temperature change induced by the corner zone of the beam path.

\begin{tabular}{cccc}
\hline Test No. & Temperature Change $\left(\Delta \mathbf{T}^{\mathbf{a}},{ }^{\circ} \mathbf{C}\right)$ & Rate of Change $^{\mathbf{b}}(\%)$ & Increase or Decrease $^{(2.5}$ \\
\hline 1 & 74 & 5.5 & Increase \\
2 & 96 & 7.2 & Increase \\
3 & 787 & 58.9 & Decrease \\
4 & 658 & 49.2 & Decrease
\end{tabular}

a Definition of $\Delta \mathrm{T}$ is seen in Figure $3 .{ }^{\mathrm{b}}$ Rate of change is defined as $(\Delta \mathrm{T} / \mathrm{T}) \times 100 \%$. T denotes the temperature at the end of the first track.

Table 4. Heating and cooling rate comparison (calculated with the first peaks in the graphs in Figure 5).

\begin{tabular}{ccccc}
\hline Test No. & $\begin{array}{c}\text { Heating Rate } \\
\left({ }^{\circ} \mathbf{C} / \mathbf{m s}\right)\end{array}$ & $\begin{array}{c}\text { Heating Rate Difference } \\
\text { According to Overlap (\%) }\end{array}$ & $\begin{array}{c}\text { Cooling Rate } \\
\left({ }^{\circ} \mathbf{C} / \mathbf{m s}\right)\end{array}$ & $\begin{array}{c}\text { Cooling Rate Difference } \\
\text { According to Overlap (\%) }\end{array}$ \\
\hline 1 & 227 & 130 & 52 & 150 \\
2 & 521 & & 130 & 150 \\
3 & 227 & 130 & 52 & 130 \\
4
\end{tabular}


(a)

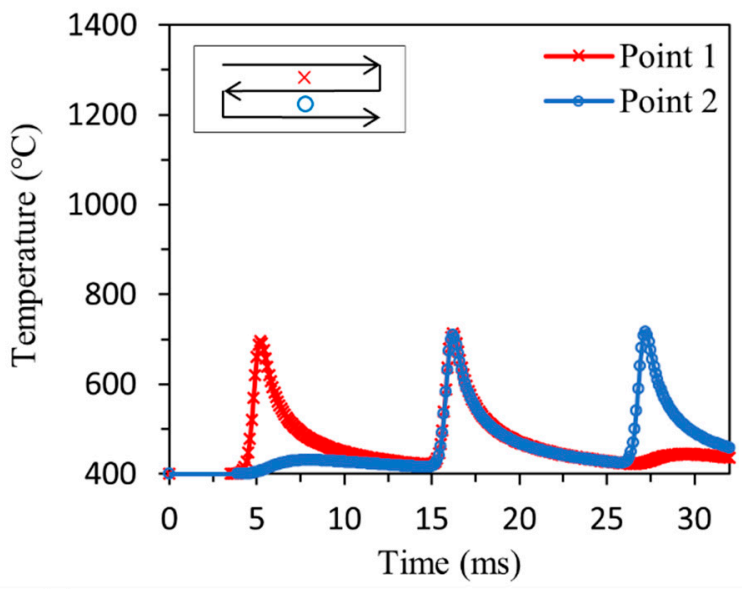

(c)

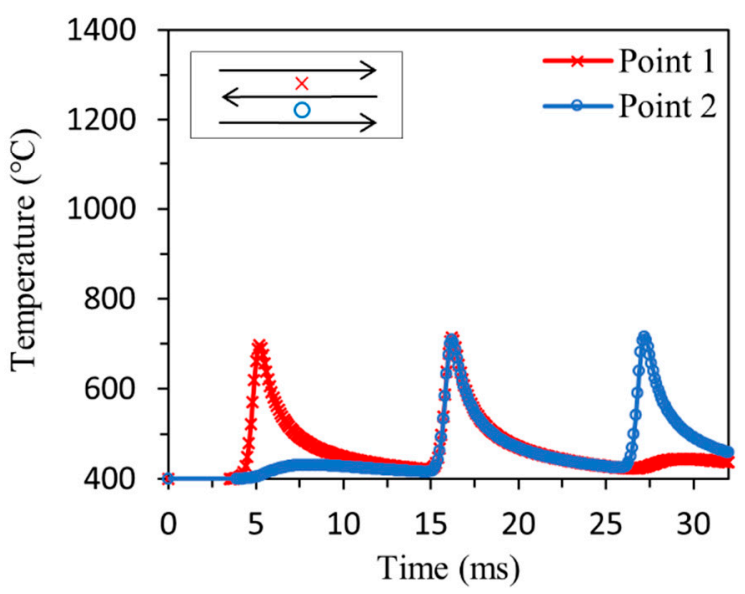

(b)

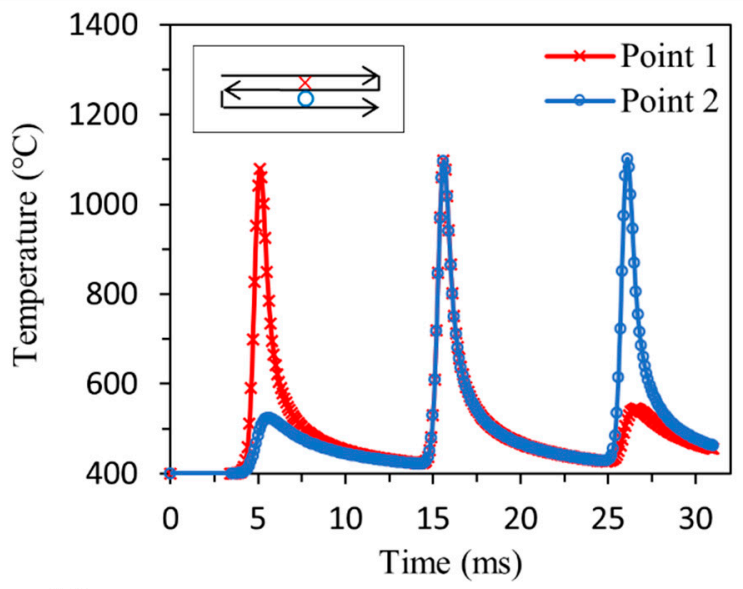

(d)

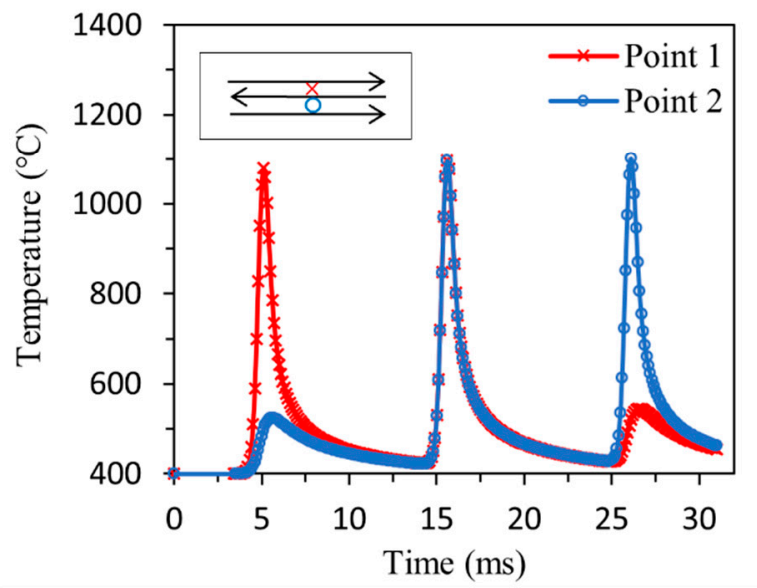

Figure 4. Temporal temperature profile obtained at midpoints between two adjacent scanned lines: (a) test 1, (b) test 2, (c) test 3 and (d) test 4 (cross and circle mark in the figure indicate point 1 and point 2, respectively).

\subsection{Analysis of the Temperature Distribution along the Depth Direction}

Figure 5 shows the temperature distributions along the depth direction for the simulation conditions in tests 1 and 2 . The temperature distributions are obtained at the points marked in the inset of Figure 5. The temperature distribution at point 2 was obtained when the laser beam reached the midpoint of the second scan track. As shown in the figure, temperature decreases significantly near the surface; however, the decrease of the temperature is alleviated as the depth increases. It was also found that at a depth of approximately $400 \mu \mathrm{m}$, the temperature becomes closer to initial condition $\left(400{ }^{\circ} \mathrm{C}\right)$. The temperature distributions at the first (point 1) and third (point 3) scan tracks are nearly identical for both the $0 \%$ and $50 \%$ overlap ratios. This indicates that the temperature distribution along the depth direction in the scan tracks is nearly uniform regardless of the number of scanning paths or the overlap ratio. The temperature gradients between the surface and at a depth of $100 \mu \mathrm{m}$ depth for the first and third scan tracks at an overlap ratio of $0 \%$ are approximately $6.07^{\circ} \mathrm{C} / \mu \mathrm{m}$. For the overlap ratio of $50 \%$, the temperature gradient is also similar for the first and third scan tracks. In the region where the beam overlap (point 2), the temperature gradient is relatively low compared to that obtained in the scan tracks due to the low surface temperature in the overlapped region. For the $0 \%$ overlap ratio, it is $\sim 1.3^{\circ} \mathrm{C} / \mu \mathrm{m}$, which is very gentle, but it increases to $\sim 4.07^{\circ} \mathrm{C} / \mu \mathrm{m}$ at an overlap $50 \%$. According to the simulation results, the temperature changes greatly along the $\mathrm{y}$ and depth (or $\mathrm{z}$ ) direction. Because dopant activation and diffusion are highly dependent on the temperature, it is 
expected that the dopant activation and diffusion outcomes will vary considerably along the $\mathrm{y}$ and $\mathrm{z}$ direction.
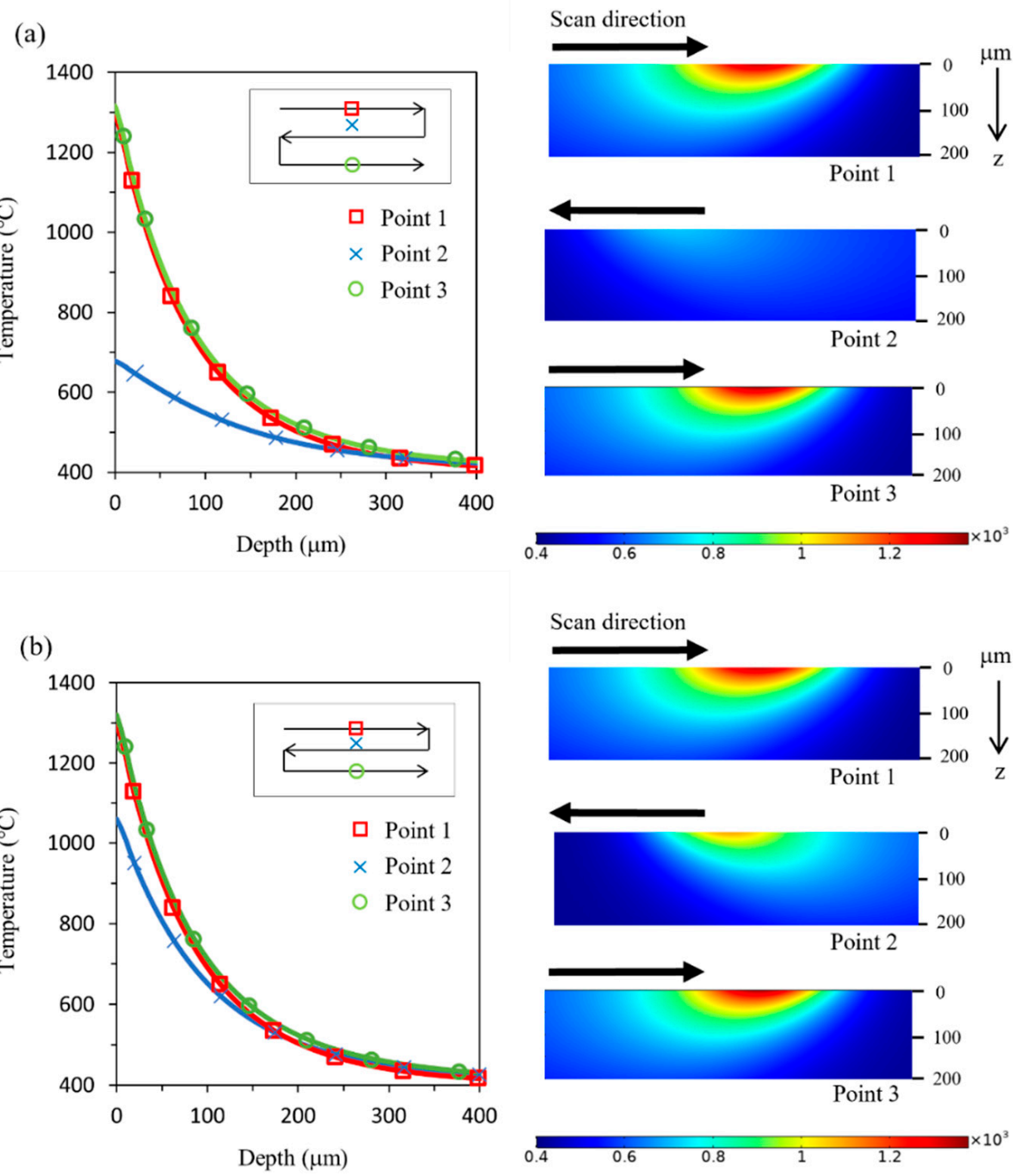

Figure 5. Temperature distribution along the depth direction: (a) test 1 and (b) test 2.

\subsection{Analysis of the Dopant Concentration Distribution}

In this work, the dopant diffusivity and concentration were investigated in relation to the process conditions using a zig-zag pattern and a beam overlap ratio of $50 \%$. In this case, the temperatures at three specific points were measured to determine the diffusivity and concentration profile at each corresponding locations within the scanned area. The first temperature $\left(1337^{\circ} \mathrm{C}\right)$ was taken at the end of the first track, the second temperature $\left(1433{ }^{\circ} \mathrm{C}\right)$ was taken from the peak point (hot spot) of the temperature profile shown in Figure $3 b$, and the third temperature $\left(1100{ }^{\circ} \mathrm{C}\right)$ was taken from the peak point of the temperature profile for point 1 (beam overlap area) shown in Figure $5 \mathrm{~b}$. In order to ascertain the diffusivity at the corresponding locations, an Arrhenius plot of the phosphorus diffusivity was obtained using Equation (10), as shown in Figure 6. Further, also in Figure 6, the diffusivity of the dopant is shown to increase with an increase in the temperature. Based on the Arrhenius plot, the diffusivity were determined for the temperatures of $1100^{\circ} \mathrm{C}$, $1337^{\circ} \mathrm{C}$ and $1433^{\circ} \mathrm{C}$. These are $1.83 \times 10^{-10} \mathrm{~cm}^{2} / \mathrm{s}$ for $1100^{\circ} \mathrm{C}, 5.46 \times 10^{-9} \mathrm{~cm}^{2} / \mathrm{s}$ for $1337^{\circ} \mathrm{C}$ and $1.53 \times 10^{-8} \mathrm{~cm}^{2} / \mathrm{s}$ for $1433{ }^{\circ} \mathrm{C}$. 


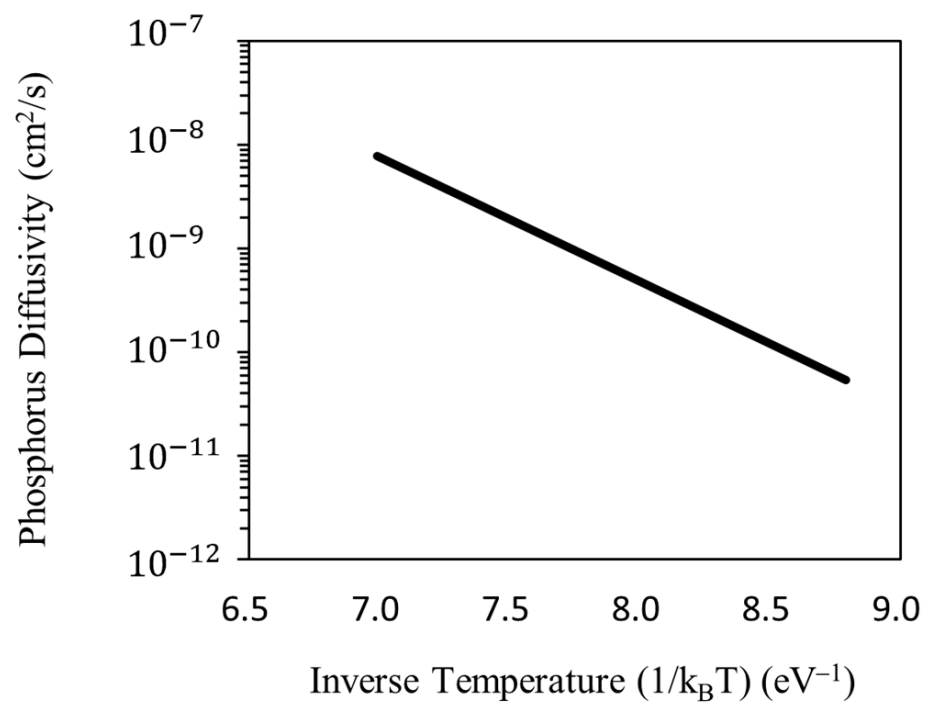

Figure 6. Arrhenius plot of phosphorus diffusivity.

Based on these diffusivities, the phosphorus concentration distribution was determined using Equation (9), as shown in Figure 7. From Figure 7, phosphorus diffusion in the depth direction increases with the temperature. The concentration profile for the $1100{ }^{\circ} \mathrm{C}$ (beam overlapped region) condition is nearly identical to that of the as-implanted case, which indicates that phosphorus diffusion is very limited in the beam overlap area. However, at a hot spot $\left(1433^{\circ} \mathrm{C}\right)$ with a temperature above the melting point $\left(1414^{\circ} \mathrm{C}\right)$ of silicon, phosphorus diffusion in the depth direction is significantly increased.

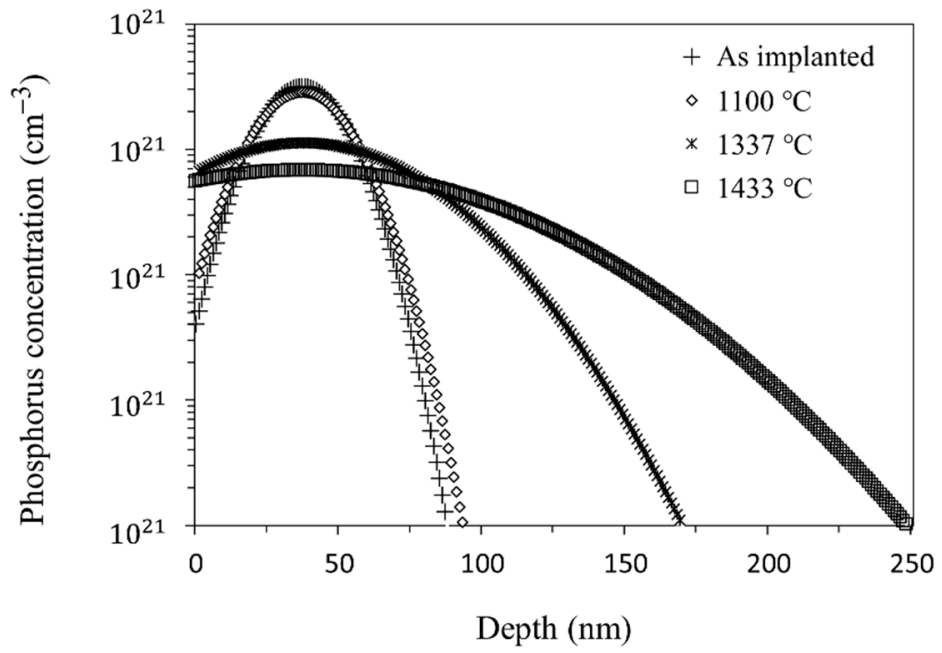

Figure 7. Phosphorus concentration distributions obtained at different temperature conditions.

Assuming that the junction depth is a depth at which the concentration of the dopant is equal to $1 \times 10^{18} \mathrm{~cm}^{-3}$, the junction depths obtained for the temperatures of $1100{ }^{\circ} \mathrm{C}$, $1337^{\circ} \mathrm{C}$ and $1433^{\circ} \mathrm{C}$ are around $84 \mathrm{~nm}, 146 \mathrm{~nm}$, and $208 \mathrm{~nm}$, respectively. For the asimplanted case, the diffusion length obtained in the temperature range of $1100-1433^{\circ} \mathrm{C}$ is between 4 and $128 \mathrm{~nm}$. For the hot spot, the diffusion length increased by nearly thirty times compared to that of the overlapped area. This major difference in the diffusion length of the dopant can lead to critical problems within a semiconductor device. Accordingly, the most appropriate process condition should be selected to improve the temperature uniformity and minimize the effects of the hot spot. 


\section{Conclusions}

In this study, a numerical simulation of the LTA process was carried out using a three-dimensional transient heat transfer model. Through the simulation, the temperature distributions induced by different laser scan paths and beam overlap ratios were analyzed. In addition, the dopant diffusion behavior outcomes at various locations having different temperature distributions within the annealed area were numerically investigated. The major conclusions of this study are presented below.

(1) According to simulation result, a zig-zag pattern produces a hot-spot around the corner part of the beam path due to the greater heat accumulation per unit area. At an overlap ratio of $50 \%$, the temperature difference induced by the corner is close to $96^{\circ} \mathrm{C}$, which is larger than that produced in the $0 \%$ overlap condition $\left(\sim 74^{\circ} \mathrm{C}\right)$. Unlike the zig-zag pattern, a bidirectional pattern generates a cold spot around the corner part of the beam path because the laser beam is switched off while moving along the $y$-direction. For the bidirectional pattern, the temperature difference induced at an overlap ratio of $0 \%\left(\sim 787^{\circ} \mathrm{C}\right)$ is larger than that produced when the overlap ratio is $50 \%\left(\sim 658^{\circ} \mathrm{C}\right)$.

(2) Regarding the beam overlap region, the temperature change induced by the overlap ratio is much more significant than the corresponding scanning pattern. The maximum temperature reachable in the beam overlap region is between $697^{\circ} \mathrm{C}$ and $1100{ }^{\circ} \mathrm{C}$ depending on the process condition, an outcome much lower than that $\left(1337-1433^{\circ} \mathrm{C}\right)$ obtained along the beam scanning path. Considering the maximum temperature reachable throughout the computational domain, it can be concluded that the most uniform heating is possible when the zig-zag pattern and the $50 \%$ overlap condition are used.

(3) According to an analysis of the temperature distribution in the depth direction, the temperature decreases considerably near the surface; however, the change of the temperature is greatly reduced as the depth increases. Around a depth of $400 \mu \mathrm{m}$, the temperature becomes close to the wafer preheating condition $\left(400{ }^{\circ} \mathrm{C}\right)$. It was found that the temperature distribution obtained at the scan track is nearly identical regardless of the order of the scan track and the overlap ratio. However, the temperature distribution obtained in the beam overlap region depended somewhat on the overlap ratio.

(4) According to dopant diffusion and concentration distribution analyses, it was found that for the hot spot produced by the zig-zag pattern and a $50 \%$ overlap ratio, the diffusion length increases by thirty times compared to the overlapped area.

(5) In this study, only the numerical simulation for multipath laser dopant activation anneal process was handled. The authors of this study are planning to undertake experimental study for the process as a future work. One of the major research items in the future work is the experimental measurement of the dopant concentration distribution through secondary ion mass spectrometry (SIMS) analysis. Experimentally measured data will be also compared to simulation results for validation of the simulation study.

Author Contributions: D.C., Methodology, Visualization, Investigation, Data curation, Writingoriginal draft. J.S., Conceptualization, Methodology, Resources, Writing-review \& editing. All authors have read and agreed to the published version of the manuscript.

Funding: This research work was supported by the Technology Innovation Program (Grant No. 20010323, Development of the Rapid Annealing System for Semiconductor Device Using kW Fiber Laser) funded by the Ministry of Trade, Industry \& Energy (MOTIE, Korea).

Institutional Review Board Statement: Not applicable.

Informed Consent Statement: Not applicable.

Data Availability Statement: Data are available from the corresponding authors upon reasonable request. 
Acknowledgments: Not applicable.

Conflicts of Interest: The authors declare no conflict of interest.

\section{References}

1. Hsu, W.; Wen, F.; Wang, X.; Wang, Y.; Dolocan, A.; Roy, A.; Kim, T.; Tutuc, E.; Banerjee, S.K. Laser spike annealing for shallow junctions in Ge CMOS. IEEE Trans. Electron. Dev. 2016, 64, 346-352. [CrossRef]

2. Chang, H.-Y.; Wu, Y.-C.S.; Chang, C.-H.; Lin, K.-L.; Joshi, A.; Basol, B.M. Nano-scale depth profiles of electrical properties of phosphorus doped silicon for ultra-shallow junction evaluation. IEEE Trans. Semicond. Manuf. 2021, 34, 357-364. [CrossRef]

3. Baik, S.; Kwon, D.-J.; Kang, H.; Jang, J.E.; Jang, J.; Kim, Y.S.; Kwon, H.-J. Conformal and ultra shallow junction formation achieved using a pulsed-laser annealing process integrated with a modified plasma assisted doping method. IEEE Access 2020, 8 , 172166-172174. [CrossRef]

4. Li, J.; Cheng, R.; Liu, C.; Zhang, P.; Lu, J.; Chen, K.; Zhang, R.; Zhao, Y. High performance Ge ultra-shallow junctions fabricated by a novel formation technique featuring spin-on dopant and laser annealing for sub-10nm technology applications. Microelectron. Eng. 2017, 168, 1-4. [CrossRef]

5. Alba, P.A.; Aubin, J.; Perrot, S.; Mazzamuto, F.; Grenier, A.; Kerdilès, S. Solid phase recrystallization induced by multi-pulse nanosecond laser annealing. Appl. Surf. Sci. Adv. 2021, 3, 100053. [CrossRef]

6. Shima, A.; Hiraiwa, A. Ultra-shallow junction formation by non-melt laser spike annealing and its application to complementary metal oxide semiconductor devices in 65-nm node. Jpn. J. Appl. Phys. 2006, 45, 5708-5715. [CrossRef]

7. Kim, J.H.; Ji, H.M.; Nguyen, M.C.; Nguyen, A.H.T.; Kim, S.W.; Baek, J.Y.; Kim, J.Y.; Choi, R.N. Low-temperature dopant activation using nanosecond ultra-violet laser annealing for monolithic 3D integration. Thin Solid Film 2021, 735, 138864. [CrossRef]

8. Timans, P.; Gelpey, J.; McCoy, S.; Lerch, W.; Paul, S. Millisecond annealing: Past, present and future. Master. Res. Soc. Symp. Proc. 2006, 912, 3-14. [CrossRef]

9. Shetty, S.; Jain, A.; Owen, D.M.; Mileham, J.; Hebb, J.; Wang, Y. Impact of laser spike annealing dwell time on wafer stress and photolithography overlay errors. In Proceedings of the 2009 International Workshop on Junction Technology, Kyoto, Japan, 11-12 June 2009; pp. 119-122. [CrossRef]

10. Skorupa, W.; Panknin, D.; Voelskow, M.; Anwand, W.; Gebel, T.; Yankov, R.A.; Paul, S.; Lerch, W.; Ferro, G.; Monteil, Y.; et al Advanced thermal processing of semiconductor materials by flash lamp annealing. In Proceedings of the 200513 th International Conference on Advanced Thermal Processing of Semiconductors, Santa Barbara, CA, USA, 4-7 October 2005; Volume 810, pp. C4.16.1-C4.16.6. [CrossRef]

11. Lanzerath, F.; Buca, D.; Trinkaus, H.; Goryll, M.; Mantl, S.; Knoch, J.; Breuer, U.; Skorupa, W.; Ghyselen, B. Boron activation and diffusion in silicon and strained silicon-on-insulator by rapid thermal and flash lamp annealings. J. Appl. Phys. 2008, 104, 44908. [CrossRef]

12. Rebohle, L.; Prucnal, S.; Skorupa, W. A review of thermal processing in the subsecond range: Semiconductors and beyond. Semicond. Sci. Technol. 2016, 31, 103001. [CrossRef]

13. Oliveira, J.; Shen, J.; Zeng, Z.; Park, J.M.; Choi, Y.T.; Schell, N.; Maawad, E.; Zhou, N.; Kim, H.S. Dissimilar laser welding of a CoCrFeMnNi high entropy alloy to 316 stainless steel. Scr. Mater. 2022, 206, 114219. [CrossRef]

14. Oliveira, J.; Shen, J.; Escobar, J.; Salvador, C.; Schell, N.; Zhou, N.; Benafan, O. Laser welding of H-phase strengthened Ni-rich NiTi-20Zr high temperature shape memory alloy. Mater. Des. 2021, 202, 109533. [CrossRef]

15. Luong, G.V.; Wirths, S.; Stefanov, S.; Holländer, B.; Schubert, J.; Conde, J.C.; Stoica, T.; Breuer, U.; Chiussi, S.; Goryll, M.; et al. Study of dopant activation in biaxially compressively strained SiGe layers using excimer laser annealing. J. Appl. Phys. 2013, 113, 204902. [CrossRef]

16. Shayesteh, M.; Connell, D.O.; Gity, F.; Murphy-Armando, F.; Yu, R.; Huet, K.; Toque-Tresonne, I.; Cristiano, F.; Boninelli, S.M.C.; Henrichsen, H.H.; et al. Optimized laser thermal annealing on germanium for high dopant activation and low leakage current. IEEE Trans. Electron Devices 2014, 61, 4047-4055. [CrossRef]

17. Shima, A.; Wang, Y.; Talwar, S.; Hiraiwa, A. Ultra-shallow junction formation by non-melt laser spike annealing for 50-nm gate CMOS. In Proceedings of the Digest of Technical Papers. 2004 Symposium on VLSI Technology, Honolulu, HI, USA, 15-17 June 2004; pp. 174-175. [CrossRef]

18. Wang, Y.; Chen, S.; Shen, M.; Wang, X.; Zhou, S.; Hebb, J.; Owen, D. Dual beam laser spike annealing technology. In Proceedings of the 2010 International Workshop on Junction Technology Extended Abstracts, Shanghai, China, 10-11 May 2010; pp. 18-23. [CrossRef]

19. Jung, S.M.; Park, C.J.; Jeong, H.; Shin, M.W. Effect of number of laser pulses on $\mathrm{p}+/ \mathrm{n}$ silicon ultra-shallow junction formation during non-melt ultra-violet laser thermal annealing. Mater. Sci. Semicond. Process. 2017, 60, 34-39. [CrossRef]

20. Florakis, A.; Papadimitriou, A.; Chatzipanagiotis, N.; Misra, N.; Grigoropoulos, C.; Tsoukalas, D. Formation of silicon ultra shallow junction by non-melt excimer laser treatment. Solid-State Electron. 2010, 54, 903-908. [CrossRef]

21. Shin, H.; Lee, M.; Ko, E.; Ryu, H.-Y.; Park, S.; Kim, E.; Ko, D.-H. Dopant activation of in situ phosphorus-doped silicon using multi-pulse nanosecond laser annealing. Phys. Status Solidi (a) 2020, 217, 1900988. [CrossRef]

22. Colin, A.; Morin, P.; Cacho, F.; Bono, H.; Beneyton, R.; Bidaud, M.; Mathiot, D.; Fogarassy, E. Simulation of the sub-melt laser anneal process in 45 CMOS technology-Application to the thermal pattern effects. Mater. Sci. Eng. B-Adv. 2008, 154-155, 31-34. [CrossRef] 
23. Caninenberg, M.; Verheyen, E.; Kiesler, D.; Stoib, B.; Brandt, M.; Benson, N.; Schmechel, R. Sample temperature profile during the excimer laser annealing of silicon nanoparticles. Opt. Laser Technol. 2015, 74, 132-137. [CrossRef]

24. Feng, L.M.; Wang, Y.; Markle, D.A. Minimizing pattern dependency in millisecond annealing. In Proceedings of the 2006 International Workshop on Junction Technology, Shanghai, China, 15-16 May 2006; pp. 25-30. [CrossRef]

25. Lee, Y.-J.; Cho, T.-C.; Sung, P.-J.; Kao, K.-H.; Hsueh, F.-K.; Hou, F.-J.; Chen, P.-C.; Chen, H.-C.; Wu, C.-T.; Hsu, S.-H.; et al. High performance poly $\mathrm{Si}$ junctionless transistors with sub-5 $\mathrm{nm}$ conformally doped layers by molecular monolayer doping and microwave incorporating $\mathrm{CO}_{2}$ laser annealing for 3D stacked ICs applications. In Proceedings of the 2015 IEEE International Electron Devices Meeting (IEDM), Washington, DC, USA, 7-9 December 2015; pp. 6.2.1-6.2.4. [CrossRef]

26. Narayan, J.; James, R.B.; Holland, O.W.; Aziz, M.J. Pulsed excimer and $\mathrm{CO}_{2}$ laser annealing of ion-implanted silicon. J. Vac. Sci. Technol. A 1985, 3, 1836-1838. [CrossRef]

27. Stathopoulos, S.; Tsetseris, L.; Pradhan, N.; Colombeau, B.; Tsoukalas, D. Millisecond non-melt laser annealing of phosphorus implanted germanium: Influence of nitrogen co-doping. J. Appl. Phys. 2015, 118, 135710. [CrossRef]

28. Florakis, A.; Verrelli, E.; Giubertoni, D.; Tzortzis, G.; Tsoukalas, D. Non-melting annealing of silicon by CO2 laser. Thin Solid Films 2010, 518, 2551-2554. [CrossRef]

29. Spitzer, W.; Fan, H.Y. Infrared Absorption inn-Type Silicon. Phys. Rev. 1957, 108, 268-271. [CrossRef]

30. Boyd, I.W.; Binnie, T.D.; Wilson, J.I.B.; Colles, M.J. Absorption of infrared radiation in silicon. J. Appl. Phys. 1984, 55, 3061-3063. [CrossRef]

31. Blomberg, M.; Naukkarinen, K.; Tuomi, T.; Airaksinen, V.-M.; Luomajärvi, M.; Rauhala, E. Substrate heating effects in $\mathrm{CO}_{2}$ laser annealing of ion-implanted silicon. J. Appl. Phys. 1983, 54, 2327. [CrossRef]

32. de Unamuno, S.; Fogarassy, E. A thermal description of the melting of c- and a-silicon under pulsed excimer lasers. Appl. Surf. Sci. 1989, 36, 1-11. [CrossRef]

33. Ceperley, D.P.; Neureuther, A.R.; Hawryluk, A.M.; Wang, X.; Shen, M.; Wang, Y. Wavelength and polarization dependent absorbtion effects in millisecond annealing of metal gate structures. In Proceedings of the 2008 16th IEEE International Conference on Advanced Thermal Processing of Semiconductors, Las Vegas, NV, USA, 30 September-3 October 2008; pp. 211-217. [CrossRef]

34. Plummer, J.D.; Deal, M.D.; Griffin, P.B. Silicon VLSI technology; Prentice Hall: Hoboken, NJ, USA, 2000; pp. 451-458.

35. Gibbons, J. Ion implantation in semiconductors-Part I: Range distribution theory and experiments. Proc. IEEE 1968, 56, $295-319$. [CrossRef]

36. Tsouroutas, P.; Tsoukalas, D.; Zergioti, I.; Cherkashin, N.; Claverie, A. Diffusion and activation of phosphorus in germanium. Mater. Sci. Semicond. Process. 2008, 11, 372-377. [CrossRef] 